\title{
Group-Contribution based Property Estimation and Uncertainty analysis for Flammability-related Properties
}

Frutiger, Jerome; Marcarie, Camille; Abildskov, Jens; Sin, Gürkan

Published in:

Journal of Hazardous Materials

Link to article, DOI:

10.1016/j.jhazmat.2016.06.018

Publication date:

2016

Document Version

Peer reviewed version

Link back to DTU Orbit

Citation (APA):

Frutiger, J., Marcarie, C., Abildskov, J., \& Sin, G. (2016). Group-Contribution based Property Estimation and Uncertainty analysis for Flammability-related Properties. Journal of Hazardous Materials, 318, 783-793. https://doi.org/10.1016/j.jhazmat.2016.06.018

\section{General rights}

Copyright and moral rights for the publications made accessible in the public portal are retained by the authors and/or other copyright owners and it is a condition of accessing publications that users recognise and abide by the legal requirements associated with these rights.

- Users may download and print one copy of any publication from the public portal for the purpose of private study or research.

- You may not further distribute the material or use it for any profit-making activity or commercial gain

- You may freely distribute the URL identifying the publication in the public portal 


\section{Accepted Manuscript}

Title: Group-Contribution based Property Estimation and Uncertainty analysis for Flammability-related Properties

Author: Jérôme Frutiger Camille Marcarie Jens Abildskov Gürkan Sin

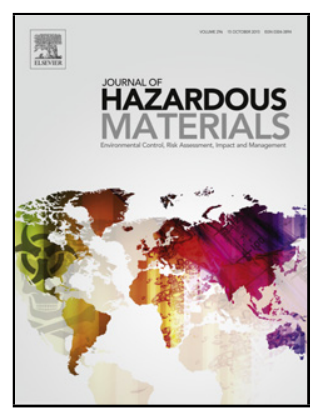

PII:

S0304-3894(16)30573-8

DOI: http://dx.doi.org/doi:10.1016/j.jhazmat.2016.06.018

Reference: HAZMAT 17807

To appear in: Journal of Hazardous Materials

Received date: $\quad 30-3-2016$

Revised date: 20-5-2016

Accepted date: $\quad 8-6-2016$

Please cite this article as: Jérôme Frutiger, Camille Marcarie, Jens Abildskov, Gürkan Sin, Group-Contribution based Property Estimation and Uncertainty analysis for Flammability-related Properties, Journal of Hazardous Materials http://dx.doi.org/10.1016/j.jhazmat.2016.06.018

This is a PDF file of an unedited manuscript that has been accepted for publication. As a service to our customers we are providing this early version of the manuscript. The manuscript will undergo copyediting, typesetting, and review of the resulting proof before it is published in its final form. Please note that during the production process errors may be discovered which could affect the content, and all legal disclaimers that apply to the journal pertain. 


\section{Group-Contribution based Property Estimation and}

\section{Uncertainty analysis for Flammability-related}

\section{Properties}

Jérôme Frutiger, Camille Marcarie, Jens Abildskov, Gürkan Sin*

The CAPEC-PROCESS Research Center, Department of Chemical and Biochemical

Engineering, Technical University of Denmark (DTU), Building 229, DK-2800 Lyngby,

Denmark

*corresponding author 
Graphical abstract

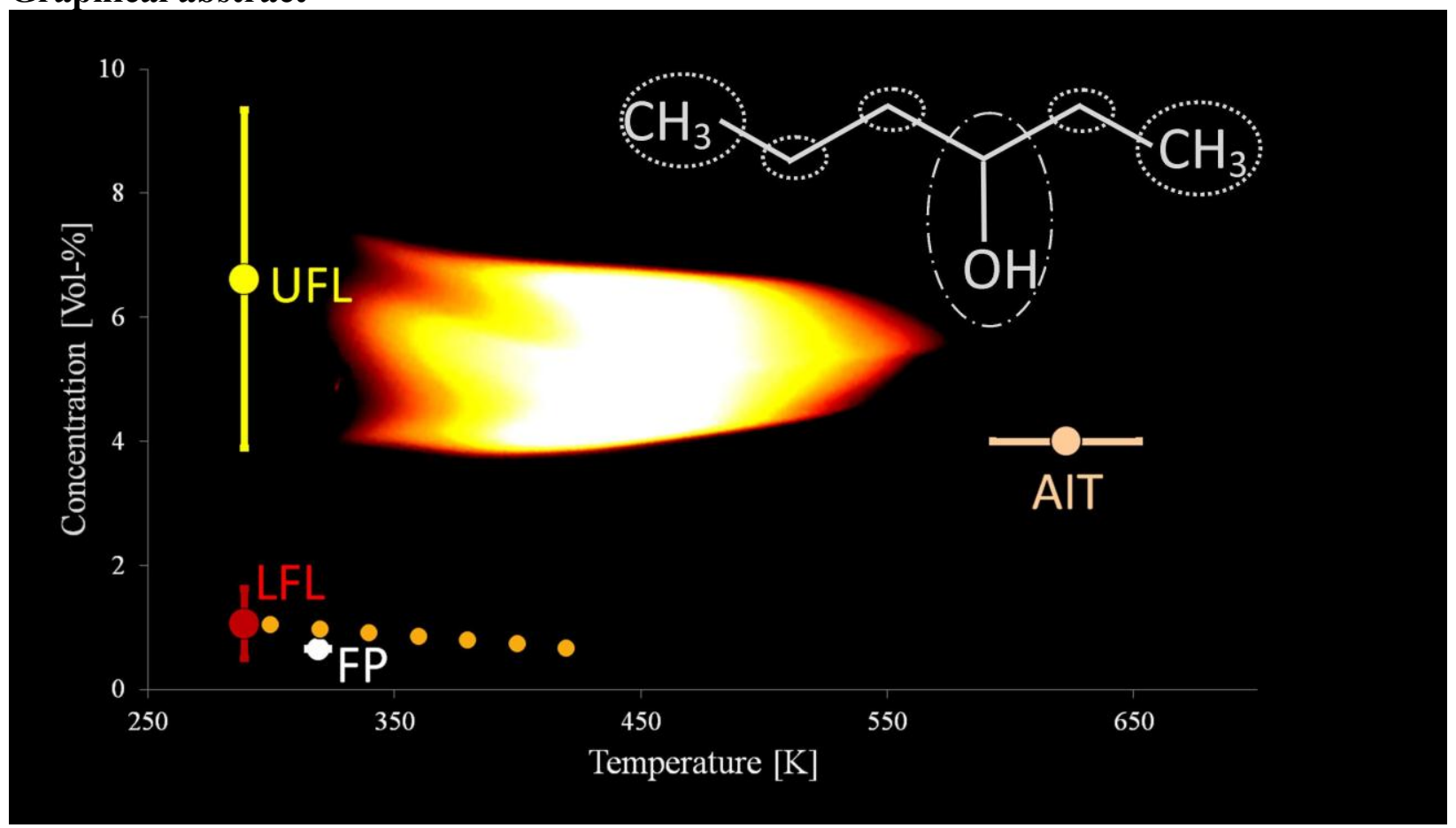




\section{Group-Contribution based Property Estimation and Uncertainty analysis for Flammability-related Properties}

Jérôme Frutiger, Camille Marcarie, Jens Abildskov, Gürkan Sin*

The CAPEC-PROCESS Research Center, Department of Chemical and Biochemical

Engineering, Technical University of Denmark (DTU), Building 229, DK-2800 Lyngby,

Denmark

*corresponding author

\section{Highlights}

1) Novel group contribution model for lower and upper flammability limit

2) Reporting 95\%-confidence interval of predicted value for safety-related properties

3) Simple approach to describe temperature-dependent lower flammability limit

4) Robust parameter regression and thorough uncertainty analysis

5) Improved group contribution factors for flash point and auto ignition temperature 


\begin{abstract}
This study presents new group contribution (GC) models for the prediction of Lower and Upper Flammability Limits (LFL and UFL), Flash Point (FP) and Auto Ignition Temperature (AIT) of organic chemicals applying the Marrero/Gani (MG) method. Advanced methods for parameter estimation using robust regression and outlier treatment have been applied to achieve high accuracy. Furthermore, linear error propagation based on covariance matrix of estimated parameters was performed. Therefore, every estimated property value of the flammability-related properties is reported together with its corresponding 95\%-confidence interval of the prediction. Compared to existing models the developed ones have a higher accuracy, are simple to apply and provide uncertainty information on the calculated prediction. The average relative error and correlation coefficient are $11.5 \%$ and 0.99 for LFL, $15.9 \%$ and 0.91 for UFL, $2.0 \%$ and 0.99 for FP as well as $6.4 \%$ and 0.76 for AIT. Moreover, the temperature-dependence of LFL property was studied. A compound specific proportionality constant $\left(K^{L F L}\right)$ between LFL and temperature is introduced and an MG GC model to estimate $K^{L F L}$ is developed. Overall the ability to predict flammability-related properties including the corresponding uncertainty of the prediction can provide important information for a qualitative and quantitative safety-related risk assessment studies.
\end{abstract}

Keywords: Group contribution, Uncertainty, Flammability limit, Flash point, Auto ignition temperature 


\section{Introduction}

The safety characteristics of hazardous substances provide indispensable information for the risk assessment of chemical products in industrial and domestic processes. In particular flammabilityrelated properties such as the lower and upper flammability limit (LFL and UFL), the flash point (FP) and the auto ignition temperature (AIT) are important to quantify the risk of fire and explosion. In the early design phase a large amount of alternative products and processes are generally analysed, compared and ranked. Whenever experimental values are unavailable property prediction models become a valuable tool [1].

Group contribution (GC) based property models try to estimate a chemical property based on structurally dependent parameters. GC methods are known to be advantageous compared to $a b$ initio procedures, quantitative structure property relationship (QSPR) or prediction based on artificial neural networks (ANN), because they are easy to apply, computationally less demanding and have a wide application range [2]. Frutiger et al. [3] stressed the need for thorough parameter estimation and uncertainty analysis for GC models in order to obtain accurate and reliable property predictions. For safety-related properties the provision of uncertainty information (i.e. the upper and lower bound of the 95\%-confidence interval) is of particular interest, because the statistical uncertainty should be taken into account, when risk calculations are being carried out [4]. However, there is still a lack of application of uncertainty analysis techniques for safety-related property prediction.

The lower flammability limit (LFL) and the upper flammability limit (UFL) are defined as the lowest and the highest possible concentration of a substance in air at which a flammable mixture is formed. These concentrations are stated at a specific temperature (298K) and pressure (1 atm). 
However, LFL and UFL change with increasing temperature [5]. The flash point (FP) is the lowest temperature where a liquid forms an ignitable vapour-air mixture. The auto ignition temperature (AIT) is the lowest possible temperature above which a substance will ignite in air without an external ignition source [6].

The review of Vidal et al. [7] provides an overview of the abundant literature, which is available on single point calculations of LFL and FP. Rowley et al. [8] compared extensively a large variety of the developed methods to estimate LFL at a predefined temperature of 298K (single point prediction). The comparison contains purely correlation-based, GC methods and also detailed mechanistic models. Among the GC based models for LFL and UFL prediction there are several methods suggested in the literature. Shimy [9] derived formulas for different classes of chemicals relating the number of carbon atoms with LFL. Solovev et al. [10] as well as Oehley [11] used atomic indices to calculate LFL. Shebeko et al. [12] used atom and bond connectivity indices in order to model LFL and UFL of pure compounds. Kondo et al. [13][14] developed a GC method to estimate the ratio between LFL and UFL, which they called F-number. All of these methods are simple and easy to apply, but employ very little structural information on the molecules and a limited application range. Hence, the average relative error is high considering different classes of chemicals [8]. Seaton [15] developed a GC method for LFL and UFL of pure compounds. The application range of the latter method is limited by the relatively small number of functional groups. The methods of Shebeko and Seaton have been used to predict nonexperimental property values for LFL in the DIPPR 801 database [16]. Albahri [17] developed a structural GC method to predict LFL and LFL. A QSPR model for LFL has been developed by Gharagheizi [18]. Pan et al. [19][20] used topological, charge, and geometric descriptors to describe a QSPR model for LFL and UFL. Recently, Gharagheizi [21] as well as Albahri [22] 
calculated GC-factors for LFL using artificial neural networks (ANN). Furthermore, Gharagheizi [23] developed a QSPR model for UFL. In a similar approach using ANN, Lazzús [24] predicted the LFL and UFL of various organic compounds. Bagheri et al. [25] used a nonlinear machine learning model to develop a LFL QSPR method. However, the mathematical structure of the latter methods using ANN or machine learning approaches for LFL and UFL is very complex, making model building very tedious. High et al. [26] set up a simple GC model with a limited amount of groups for UFL and included estimations of the upper and lower bound of the confidence limits. Shu et al. [27] presented a method using the threshold temperature (e.g. the ignition temperature) to evaluate UFL of a hydrocarbon diluted within an inert gas. The same authors also presented a model to evaluate the flammable zones of hydrocarbon-air-CO2 mixtures based on flame temperature theory [28]. Rowley et al. [8] provided a GC method that is based on the relationship between LFL, the respective enthalpies of the substance as well as air and the adiabatic flame temperature, obtaining high accuracy. Mendiburu et al. [29][30] developed semi empirical methods for determination of LFL and UFL of C-H compounds, which took into account the stoichiometry of combustion process and the estimation of the adiabatic flame temperature. Except to High et al., none of the above mentioned methods includes a thorough uncertainty analysis. Hence, no information about the respective $95 \%$ confidence interval for a specific prediction of LFL and UFL is provided.

The temperature-dependence of LFL and UFL of organic compounds is generally depicted by the modified Burgess-Wheeler law [31], that relates LFL, temperature, the heat capacity of the fuel-air mixture and the heat of combustion $\Delta H_{c}^{\circ}$. Britton et al. [32][33] suggested correlations between LFL and the adiabatic flame temperature. Both methods assume that the adiabatic flame temperature is independent of the initial temperature, which was found to be only true for 
experimental condition, where LFL was measured in a narrow tube [8][34]. A purely empirical correlation of LFL on a wide range of temperature has been proposed by Catoire et al. [35] taking into account the corresponding stoichiometric mixture of fuel and air mixture and the number of carbon atoms in the molecule. However, the model strongly depends on the data set itself. Rowley et al. [8] improved the modified Burgess-Wheeler law by taking into account the temperature-dependence of the adiabatic flame temperature and relating it to the number of carbon atoms. However, there is only limited amount of structural information of the molecules (i.e. the carbon number) taken into account.

Hukkerikar et al. [36] developed a GC model using Marrero/Gani (MG) method for FP and AIT including an uncertainty analysis based on the parameter covariance matrix and performance criteria to assess the quality of parameter estimation. Frutiger et al. [3] developed a GC model for the heat of combustion $\Delta H_{c}^{\circ}$ taking into account different parameter regression methods, optimization algorithms, alternative uncertainty analysis methods and advanced outlier treatment. The same authors also analyzed parameter identifiability issues as the source of prediction inaccuracy and uncertainty. Furthermore, they calculated and reported the $95 \%$ confidence interval of GC model predictions (prediction accuracy). This thorough and systematic methodology led to significant improvement of GC based model development.

In this study, we therefore aim to provide a new set of improved group contribution models using Marrero/Gani (MG) method [37] to estimate LFL and UFL, FP and AIT at standard conditions using the systematic model development and analysis method of Frutiger et al. [3]. Furthermore, we suggest a GC method to include temperature-dependency in lower flammability limit calculation. The models include a thorough uncertainty analysis (i.e. estimation of the $95 \%$ confidence interval) of every prediction, in order to provide additional information on the 
reliability of the estimated property. In that sense it is possible to obtain an overall picture of the different flammability properties of a chemical based on the same property prediction methodology.

The paper is organized as follows: (i) the overall methodology for the GC model development and uncertainty analysis for single point LFL, UFL, FP and AIT is shown; (ii) the LFL model is extended to include temperature-dependence; (iii) the performances of the novel GC models are compared with that of existing models; (iv) an application example for 3-Hexanol to calculate LFL including $95 \%$ confidence interval is provided. 


\section{Method}

The procedure to develop the GC model for the single point LFL UFL, FP and AIT, to estimate its parameters and to perform the uncertainty analysis, follows the work of Frutiger et al. [3]. Robust regression method as well as the covariance based uncertainty analysis has been applied for this study. Frutiger et al. [3] suggested and compared also alternative methods for parameter estimation and uncertainty analysis, e.g. in order to take into account experimental uncertainties. GC MG factors for FP and AIT are re-estimated using robust regression and outlier treatment, aiming an improved parameter fit compared to the previous estimations [36].

\subsection{GC model functions}

As a GC model structure the Marrero/Gani (MG) [37] method is chosen, which considers structural contributions on three levels. The MG method is written as

$$
\begin{gathered}
f_{i}(X)=\sum_{j} N_{j} C_{j}+\sum_{k} M_{k} D_{k}+\sum_{l} O_{l} E_{l} \\
f(X)=T \cdot \theta
\end{gathered}
$$

A specific functional group (1st order parameters $j$ ) is expressed by the factor $C_{j}$ that occurs $N_{j}$ times. $D_{k}$ is the contribution factor of the polyfunctional (2nd order parameters $k$ ) that occurs $M_{k}$ times in the molecular structure. Finally structural groups (3rd order parameters $l$ ) are taken into account by the contribution $E_{l}$ that has $O_{l}$ occurrences. The function $f(X)$ needs to be specified for a certain property $X$. The factors can be determined for a specific molecule following the rules of Marrero et al. [37]. The GC parameters can be summarized in vector $\theta$ with $T$ being the occurrence matrix of the factors (see Eq. (2)). MG groups are shown for methacrylonitrile and adiponitrile in Figure 1. 


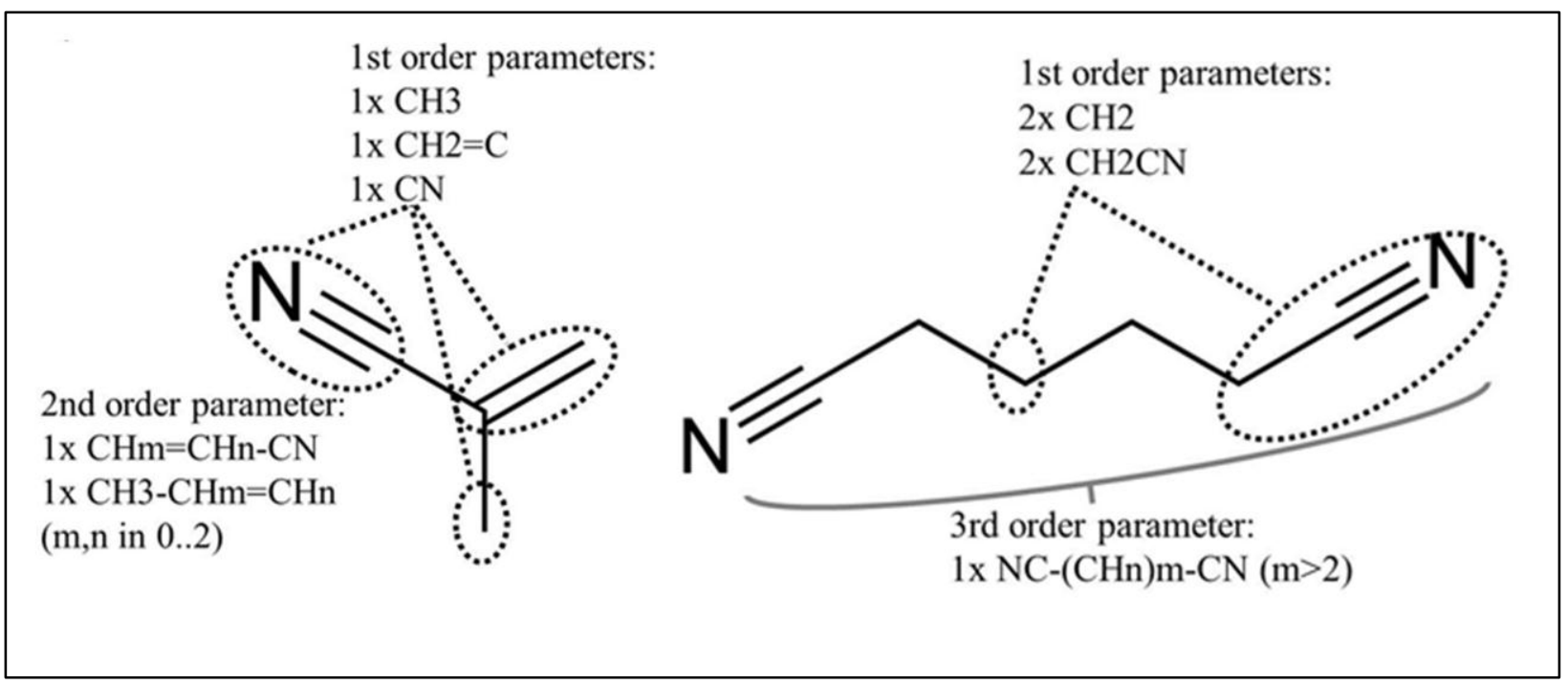

Figure 1. Example of GC-factors of methacrylonitrile (left) and adiponitrile (right).

By plotting various classes of pure components versus their increasing carbon number in homolog series one can obtain ideas regarding the property function $f(X)$. Such a homologue series plot is shown for LFL in Figure 2.

The following functions are suggested for LFL, UFL and FP for a specific compound.

$$
\begin{gathered}
f(L F L)=\log \left(\frac{L F L}{L F L_{\text {const }}}\right)=\sum_{j} N_{j} C_{j}+\sum_{k} M_{k} D_{k}+\sum_{l} O_{l} E_{l} \\
f(U F L)=\log \left(\frac{U F L}{U F L_{\text {const }}}\right)=\sum_{j} N_{j} C_{j}+\sum_{k} M_{k} D_{k}+\sum_{l} O_{l} E_{l} \\
f(F P)=F P-F P_{\text {const }}=\sum_{j} N_{j} C_{j}+\sum_{k} M_{k} D_{k}+\sum_{l} O_{l} E_{l}
\end{gathered}
$$

In Eq. (3) to (5) $L F L_{\text {const }}, U F L_{\text {const }}$, and $F P_{\text {const }}$ are universal constants that need to be determined by the parameter regression. For AIT data on the homolog series suggest a more complex structure involving two summations: 


$$
\begin{aligned}
A I T & =A I T_{\text {const } 1}+\left(\sum_{j} P_{j} X_{j}+\sum_{k} Q_{k} Y_{k}+\sum_{l} R_{l} Z_{l}\right) \\
& +A I T_{\text {const } 2} \cdot 10^{-\left(\sum_{j} N_{j} C_{j}+\sum_{k} M_{k} D_{k}+\sum_{l} O_{l} E_{l}\right)}
\end{aligned}
$$

Eq. (5) and Eq. (6) has already been proposed by Hukkerikar et al. [36]. Here more experimental data points are taken into account and a comprehensive methodology for parameter estimation and uncertainty analysis is applied to estimate the GC factors in this study. Eq (4) was first suggested by Frutiger et al. [38], but no thorough parameter estimation and uncertainty analysis has been performed.

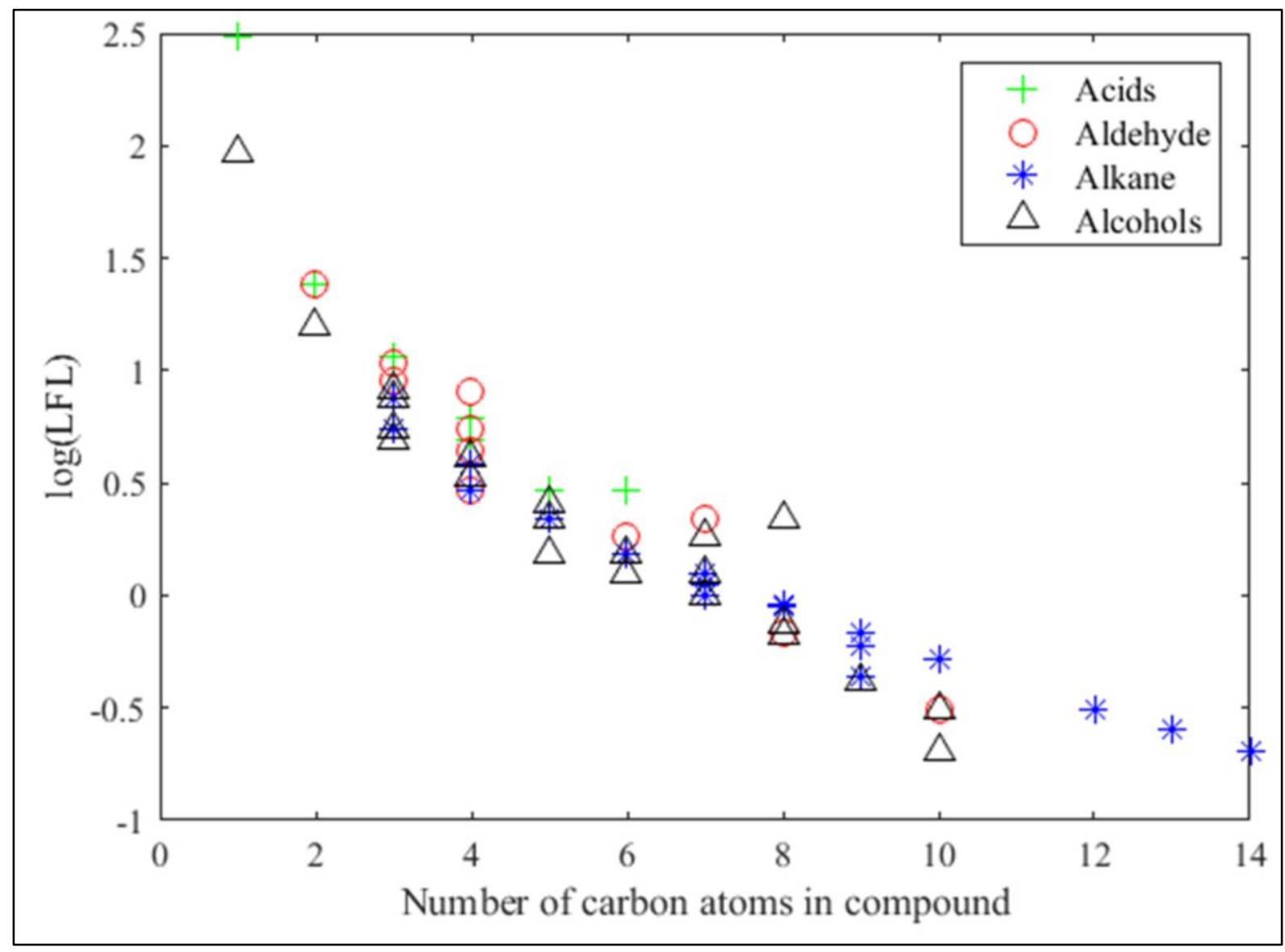

Figure 2. Graphical representation of number of carbon atoms versus property for logarithm of LFL for a selection of groups of pure components. 
In order to account for the temperature-dependence of LFL the approach of Rowley et al. [8] is used as a basis to derive a new MG GC method. The latter authors also provided a detailed derivation and explanation of the following equations.

The temperature-dependent LFL of Rowley et al. is based on the following energy balance of the combustion process:

$$
\operatorname{LFL}(T) \cdot\left(-\Delta H_{c}^{\circ}\right)+C_{p \text { fuel-air }} \cdot(T-298 K)=C_{p \text { prod }} \cdot\left(T_{a d}-298 K\right)
$$

where $\Delta H_{c}^{\circ}$ is the heat of combustion, $C_{p \text { fuel-air }}$ is the heat capacity of the compound and air $C_{p \text { prod }}$ is the heat capacity of the combustion products and $T_{a d}$ is the adiabatic flame temperature. Rowley et al. further assumed:

1) $C_{p \text { fuel-air }}$ to be roughly equal to $C_{p \text { prod }} 2$ ) the adiabatic flame temperature $T_{a d}$ as linearly decreasing with increasing initial temperature [34].

This leads to the following generalization of the Burgess-Wheeler law [8]:

$$
L F L(T) \cdot=L F L\left(T_{\text {ref }}\right)+\frac{(1-\gamma) \cdot C_{p \text { fuel-air }}}{\left(-\Delta H_{c}^{\circ}\right)} \cdot\left(T-T_{\text {ref }}\right)
$$

where $C_{p \text { fuel-air }}$ is assumed to be

$$
C_{p \text { fuel-air }}=L F L\left(T_{\text {ref }}\right) \cdot C_{p \text { fuel }}+\left(100 \%-L F L\left(T_{\text {ref }}\right)\right) \cdot C_{p \text { air }}
$$

$\gamma$ is the compound specific linear constant of $T_{a d}, C_{p \text { fuel }}$ is the heat capacity of a specific compound at the reference temperature $T_{r e f}$ and $C_{p \text { air }}$ is the heat capacity of air at the reference temperature $T_{\text {ref }}$.

Comparing experimental flammability data for different temperatures and various compounds, usually a linear dependence between LFL and the temperature $\mathrm{T}$ is reported by [5][34][39]. Based on this premise, we present a simplified model as follows: 


$$
L F L_{i}(T) \cdot=L F L_{i}\left(T_{r e f}\right)+K_{i}^{L F L} \cdot\left(T-T_{r e f}\right)
$$

where $K_{i}^{L F L}$ is the proportionality constant between LFL and T for a specific compound $i . K_{i}^{L F L}$ could be determined for a certain compound $i$ by analyzing the experimental work of Coward et al. [39] and Rowley et al. [34]. Plotting $K^{L F L}$ versus the corresponding carbon number of the compounds implies the possibility of describing this constant by GC models using a reciprocal model function (see Figure 3). Therefore, we propose the following Marrero/Gani GC model to estimate $K^{L F L}$ for a specific compound:

$$
f\left(K^{L F L}\right)=\frac{K_{\text {const }}^{L F L}}{K^{L F L}}=\sum_{j} N_{j} C_{j}
$$

with $K_{\text {const }}^{L F L}$ as the universal correlation constant and $C_{j}$ the first order parameters that occurs $N_{j}$ times.

Comparison with the generalized Burgess-Wheeler law in Eq. (8) with Eq. (10), shows that our proposed proportionality constant can be considered as a lumped parameter of several properties:

$$
K^{L F L}=\frac{(1-\gamma) \cdot C_{p \text { fuel-air }}}{\left(-\Delta H_{c}^{\circ}\right)}
$$

Calculating $K^{L F L}$ directly from GC factors reduces the amount of parameters in the model which makes it easier to apply. Furthermore, it lumps properties that showed to be correlated with increasing carbon number or structurally-dependent group contribution factors in previous studies: $C_{p \text { fuel-air }}$ is linearly depending on the heat capacities $C_{p \text { fuel }}$ and $C_{p \text { air }}$. Joback and Reid depicted the dependence of the heat capacity on the structurally dependent parameters [40]. $\Delta H_{c}^{\circ}$ is strongly depending on the carbon numbers and a MG GC method has been developed by Frutiger et al. [3]. Rowley et al. [8] showed dependence of $\gamma$ on the carbon numbers. If for a 
compound, no experimental value for the mentioned properties exist, then GC models would be used in order to estimate $C_{p \text { fuel-air }}, \Delta H_{c}^{\circ}$ and $\gamma$ by Eq. (8). In that sense the introduction of $K^{L F L}$ summarizes structural dependence on the temperature-dependent flammability for a specific compound in one single parameter and provides one single model GC model to estimate it.

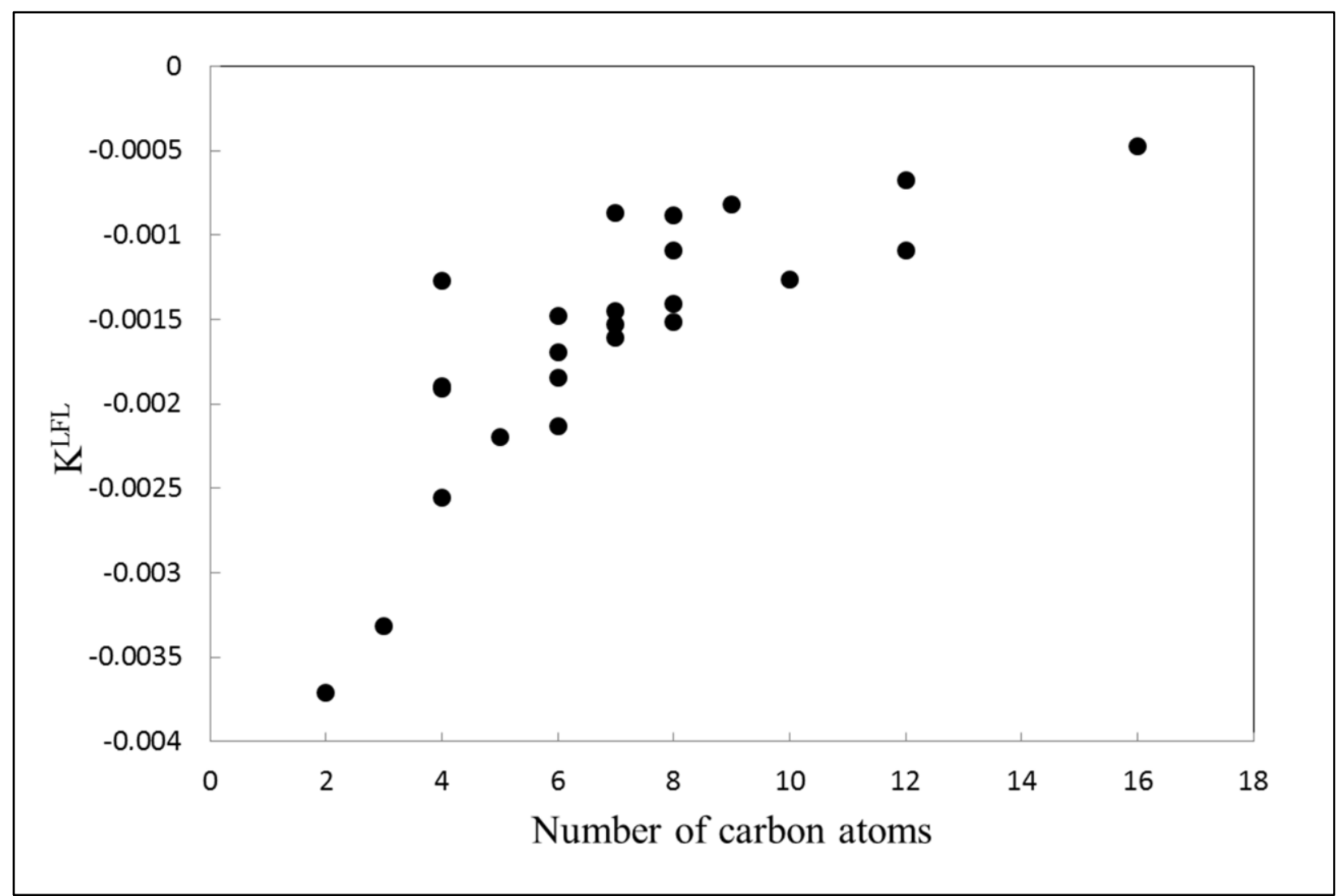

Figure 3. Graphical representation of number of carbon atoms versus $K^{L F L}$.

\subsection{GC parameter estimation and uncertainty analysis}

Experimental data for LFL, UFL, FP and AIT are taken from AIChE DIPPR 801 Database [16].

We only considered data points that are classified by DIPPR as "experimental" and "accepted" values. Table 1 shows the number of experimental data points. Data for the temperature- 
dependence of LFL have been collected from different sources [34][5][39].

Table 1. Number of compounds per property.

No. compounds

$\overline{\mathrm{LFL}}$

443

$\overline{\mathrm{UFL}}$

351

$\overline{\text { FP }}$

927

AIT

513

$K^{L F L}$

23

In order to estimate the GC parameters robust regression is chosen, in which the residuals are assigned a certain weight factor $w_{i}$, decreasing the influence of experimental data points giving large residuals (not following the model), i.e. potential outliers [41]. Robust regression has been shown to be advantageous over standard non-linear regression for the estimation of GC factors [3].

$$
\begin{gathered}
y=\left\{L F L, U F L, F P, A i T, K_{i}^{L F L}\right\} \\
\theta^{*}=\arg \min \sum_{i} w_{i} \cdot\left(y_{i}^{\text {exp }}-y_{i}^{\text {pred }}\right)^{2} \\
w_{i}=\frac{1}{1+\left(y_{i}^{\text {exp }}-y_{i}^{\text {pred }}\right)^{2}}
\end{gathered}
$$


$\theta^{*}$ is the parameter $\left(1^{\text {st }}, 2^{\text {nd }}\right.$ and $3^{\text {rd }}$ order group contributions) estimates and $y_{i}^{\text {pred }}$ is the prediction of compound $i$ according to Eq. (3) to (6) and $y_{i}^{e x p}$ its corresponding experimental value.

Outliers are identified using the empirical cumulative distribution function (CDF) of the residuals between experimental and predicted values, which has been described for GC models by Frutiger et al.[38]. The empirical CDF is defined as a step function increasing by $1 / \mathrm{n}$ in every data point. The major advantage of this methodology is that the distribution of the residuals is estimated from the data themselves, not a priori assuming normal distribution. Outliers are considered as data points that that lie below the $2.5 \%$ or above the $97.5 \%$ probability levels.

The Uncertainty analysis is based on linear error propagation using parameter covariance matrix $[3][36]$.

The covariance matrix, $C O V\left(\theta^{*}\right)$ of parameter estimators is asymptotically estimated as follows

$$
\operatorname{COV}\left(\theta^{*}\right)=\frac{S S E}{n-p}\left(J\left(\theta^{*}\right)^{T} J\left(\theta^{*}\right)\right)^{-1}
$$

where $p$ is the number of parameters, SSE is the minimum sum of squared errors given by the regression model, $n$ is the number of data points and, $J$ is the Jacobian of the model function $f$ with respect to the parameter values $\theta^{*}$. Linear error propagation allows estimating the uncertainty of the property predictions. The covariance matrix of the predictions $C O V\left(y^{\text {pred }}\right)$ can be approximated using the Jacobian and the covariance of the parameter estimates as shown in Eq. (16),

$$
C O V\left(y^{\text {pred }}\right)=J\left(\theta^{*}\right) \operatorname{COV}\left(\theta^{*}\right) J\left(\theta^{*}\right)^{T}
$$


A student $t$-distribution $t\left(n-p, \alpha_{t} / 2\right)$ (with $\alpha_{t} / 2$ percentile) can be used to calculate the confidence intervals of the property predictions

$$
y_{1-\alpha}^{\text {pred }}=y^{\text {pred }} \pm \sqrt{\operatorname{diag}\left(J\left(\theta^{*}\right) C O V\left(\theta^{*}\right) J\left(\theta^{*}\right)^{T}\right)} \cdot t\left(n-p, \alpha_{t} / 2\right)
$$

where $\operatorname{diag}\left(\operatorname{COV}\left(\theta^{*}\right)\right)$ are the diagonal elements of $\operatorname{COV}\left(\theta^{*}\right)$ and $\left.\operatorname{diag}\left(J\left(\theta^{*}\right) \operatorname{COV}\left(\theta^{*}\right) J\left(\theta^{*}\right)^{T}\right)\right)$ the diagonal elements of $\left.\operatorname{COV}\left(J\left(\theta^{*}\right) \operatorname{COV}\left(\theta^{*}\right) J\left(\theta^{*}\right)^{T}\right)\right)$.

In order to quantify and compare the performance of the parameter estimates the following statistics are calculated: the Pearson correlation coefficient $R^{2}$ and the average relative error ARE:

$$
\begin{aligned}
R^{2} & =\frac{\sum_{j}\left(y_{j}^{e x p}-y_{j}^{p r e d}\right)^{2}}{\sum_{j}\left(y_{j}^{e x p}-\mu_{y}\right)^{2}} \\
A R E & =\frac{1}{n} \sum_{j} \frac{\left(y_{j}^{e x p}-y_{j}^{p r e d}\right)}{y_{j}^{e x p}}
\end{aligned}
$$

with $y_{j}^{\text {pred }}$ the prediction of compound $j, y_{i}^{e x p}$ the experimental value and $\mu_{y}$ the mean value.

In order to compare the newly developed temperature-dependent GC model for LFL with the model developed by Rowley et al. [8] Akaike information criterion (AIC) [42] is used. AIC is a way of model selection based on information theory, which tries to account for both the goodness of the model fitting and the complexity of the model. Akaike information criterion $(A I C)$ is given by Eq. (21).

$$
A I C=-2 \cdot \log \left(\frac{S S E}{n}\right)+2 p
$$


$S S E$ is the sum of squared errors, $n$ the number of data points and $p$ the number of parameters [42]. 


\section{Results and Discussion}

\subsection{Results of the GC parameter estimation and uncertainty analysis}

The results of the parameter estimation using robust regression are shown in Table 2 and Table 3. $R^{2}$ is the Pearson correlation coefficient, $A R E$ is the average relative error, SSE is the sum of squared errors between the experimental and predicted property values and $S D$ is the standard deviation. $P_{r c} 25$ represents the percentage of the experimental data points found within $\pm 25 \%$ relative error range respectively. The performance statistics show that the GC parameter fits for LFL, UFL and $K_{i}^{L F L}$ are very good. For FP and AIT the performance statistics of the reestimated parameters can be compared to the estimation of Hukkerikar et al. [36], who used a standard non-linear regression. As it can be seen in Table 3, robust regression and systematic outlier removal gives a much better parameter fit. Figure 4 depicts the prediction based on the model of versus the experimental values used for the GC parameter estimation of LFL, UFL, FP and AIT. The GC factors of all of the developed models can be found in the supplementary material.

Table 2. Regression model performance statistics for LFL, UFL and $\gamma$.

\begin{tabular}{lccccc}
\hline & $R^{2}$ & $\begin{array}{c}A R E \\
{[\%]}\end{array}$ & $S D$ & $S S E$ & $\begin{array}{c}P_{r c} 25 \\
{[\%]}\end{array}$ \\
\hline LFL & 0.99 & 11.5 & 0.24 & 23 & 88 \\
\hline UFL & & & & & \\
& 0.91 & 15.9 & 2.74 & 77 & 82 \\
\hline$K^{L F L}$ & 0.89 & 14.7 & $6.01 \cdot 10^{-4}$ & $7.7 \cdot 10^{-6}$ & 76 \\
\hline
\end{tabular}


Table 3. Regression model performance statistics for FP and AIT.

\begin{tabular}{lccccc}
\hline & $R^{2}$ & $\begin{array}{c}\text { ARE } \\
{[\%]}\end{array}$ & $S D$ & $S S E$ & $\begin{array}{c}\text { Prc25 } \\
{[\%]}\end{array}$ \\
\hline FP & 0.99 & 2.0 & 9.99 & $4.73 \cdot 10^{5}$ & 100 \\
& & & & & \\
\hline FP (Hukkerikar et al.) & 0.80 & 3.2 & 14.30 & - & 98 \\
\hline AIT & & & & & 97 \\
\hline AIT (Hukkerikar et al.) & 0.72 & 6.8 & 56.74 & - & 96 \\
\hline
\end{tabular}

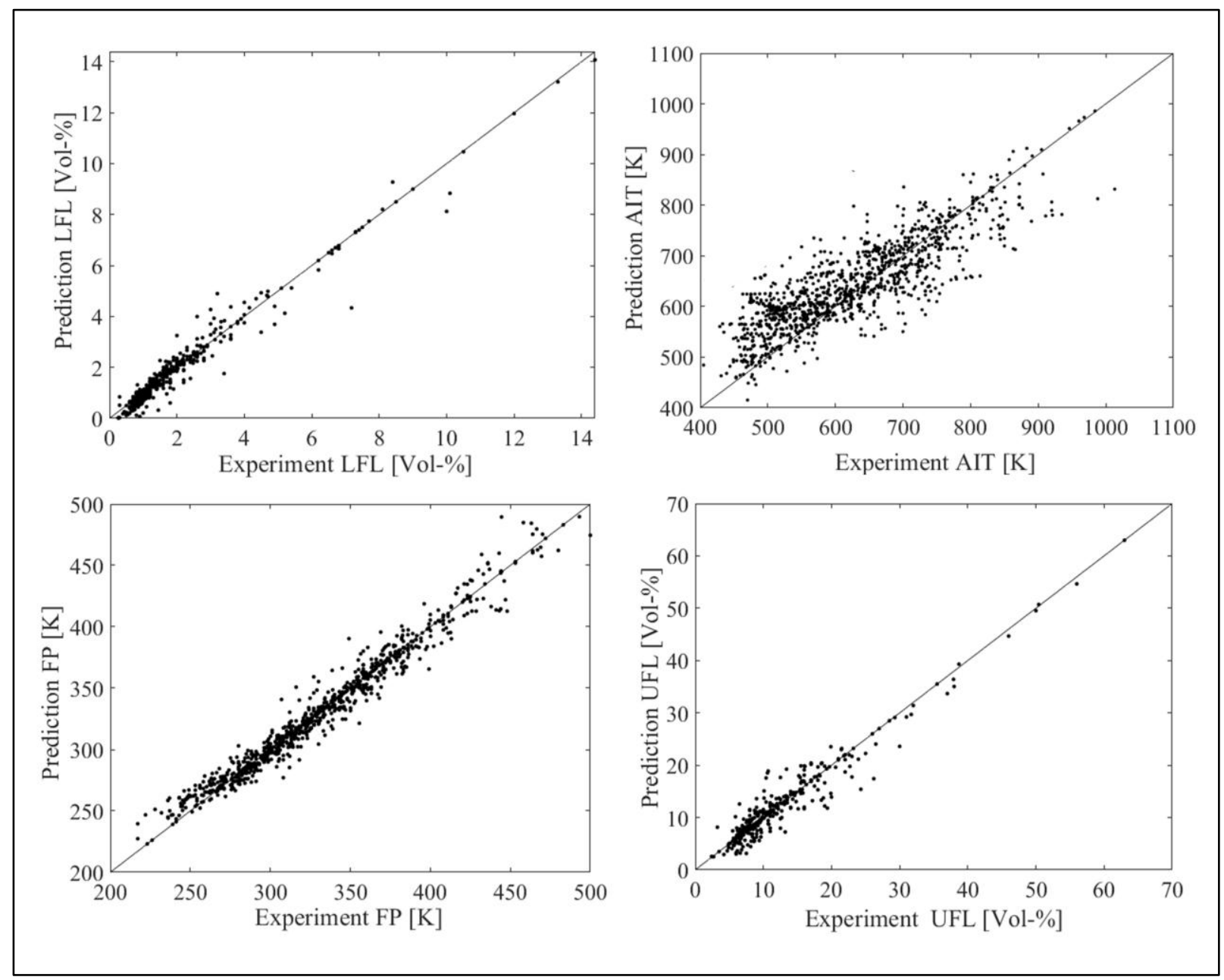

Figure 4. Prediction versus experimental value for LFL, UFL, FP and AIT. 
The average relative error $A R E$ and the number of data included in this study for the LFL and UFL model are compared to other property prediction models in Table 4 and Table 5.

Table 4. Comparison of developed LFL model with existing GC models. Abbreviations: average relative error $(A R E)$, Marrero/Gani (MG), group contribution (GC), atom and bond connectivity (AC), quantitative structure property relationship (QSPR), artificial neural networks (ANN).

\begin{tabular}{lccc}
\hline & Model structure & ARE [\%] & No. of data \\
\hline Current study & MG GC & $\mathbf{1 2}$ & $\mathbf{4 4 3}$ \\
\hline Oehley, 1953 [11] & AC & 27 & - \\
\hline Solovev et al., 1960 [10] & GC & 25 & - \\
\hline Shimy, 1970 [9] & CN & 24 & 9 \\
\hline Shebeko et al., 1983 [12] & AC & 21 & 70 \\
\hline Seaton, 1991 [15] & GC & 16 & 152 \\
\hline Kondo et al., 2001 [13] & GC & 24 & $1096^{*}$ \\
\hline Albahri, 2003 [43] & structural GC & 10 & $1038^{*}$ \\
\hline Gharagheizi, 2008 [18] & QSPR & 8 & $1056^{*}$ \\
\hline Pan et al., 2009 [19] & QSPR & 5 & 328 \\
\hline Gharagheizi, 2009 [23] & ANN & 4 & 509 \\
\hline Lazzús, 2011 [24] & ANN & 9 & $1615^{*}$ \\
\hline Rowley et al., 2011 [8] & GC & 11 & 120 \\
\hline Bagheri et al., 2012 [25] & QSPR & 9 & 1 \\
\hline Mendiburu et al., 2015 [29] & semi empirical & (15 & \\
\hline
\end{tabular}

*included experimental and predicted property values hence it is not an objective performance evaluation of a model. 
Table 5. Comparison of developed UFL model with existing GC models. Abbreviations: average relative error $(A R E)$, Marrero/Gani (MG), group contribution $(\mathrm{GC})$, atom and bond connectivity (AC), quantitative structure property relationship (QSPR), artificial neural networks (ANN).

\begin{tabular}{lccc}
\hline & Model structure & ARE [\%] & No. of data \\
\hline Current study & MG GC & $\mathbf{1 6}$ & $\mathbf{3 5 1}$ \\
\hline Shebeko et al., 1983 [12] & AC & 25 & 70 \\
\hline High et al., 1987 [26] & GC & 26 & 181 \\
\hline Seaton, 1991 [15] & GC & 20 & 152 \\
\hline Albahri, 2003 [17] & structural GC & 12 & 109 \\
\hline Pan et al., 2009 [20] & QSPR & 19 & $588^{*}$ \\
\hline Gharagheizi, 2009 [23] & QSPR & 10 & $1057^{*}$ \\
\hline Lazzús, 2011 [24] & ANN & 7 & 328 \\
\hline Mendiburu et al., 2016 [30] & semi empirical & 8 & 115 \\
\hline
\end{tabular}

*included experimental and predicted property values hence it is biased.

The comparison could only be made according to the average relative error $A R E$, due to the fact that no uncertainty analysis has been performed by the other authors. The current model provides for every predicted value the corresponding uncertainty, which is lacking in the other models (with the exception of High et al. [26]).

Considering the ARE of LFL, the model developed in this study performs better than the previous LFL models of Oehley, Solovev et al., Shimy, Shebeko et al., Seaton and Kondo et al.. Furthermore, the amount of data that are taken into account is much higher for the present model. This increases the application range of the model, since more chemicals from different classes of molecules have been used in the model development. The current LFL model performs similar in comparison to the recent GC prediction method of Rowley et al. and the best performing model of Albahri. The work of Mendiburu et al. took only $\mathrm{C}-\mathrm{H}$ compounds into account and can 
therefore not be compared directly to the model of this study. The ANN methods of Lazzús and Albahri shows better performance statistics as well. However, these authors took a lower amount of experimental data points into account for the fitting of their model. Hence, the application range is narrower. Furthermore, the ANN structure is very complex for even a relatively small number of fitted data. In that sense its applicability is more difficult and its application range is smaller. Similar conclusions can be made for UFL, where the developed model is superior to Shebeko, High et al., Seaton and Pan et al.. Albahri and Lazzús perform slightly better, but they used a smaller amount of data points, which leads to a smaller application range.

The ANN and QSPR models of Gharagheizi, Pan et al. and Bagheri et al. for LFL and UFL have a lower $A R E$ and more data points. However, the amount of data consist of all experimental data and predicted values available in the DIPPR database which is not a scientifically accepted way to compare model performance statistics. A parameter estimation should solely be based on experimental data points only [44]. While comparing ANN or QSPR with GC models for flammability, it is important to state that ANN/QSPR and are fundamentally different to GC methods in the sense that the aim is to build the best possible model structure (i.e. considering variables and descriptors). However, the model structure is fixed in GC methods and its goal is to estimate the parameters in the best possible way given a certain available set of experimental data. The structure of the MG GC model is much simpler compared to ANN and easier to apply in practice. Furthermore, whereas the reliability of the GC model predictions have been statistically demonstrated and verified against application in practice, establishing the reliability and confidence of parameter estimation in ANN or QSPR remains to be demonstrated. Furthermore, GC models allow adding new experimental values to the parameter estimation 
without changing the model structure. In QSPR and ANN model building need to be performed all over again [3].

GC factors for the LFL, UFL, AIT, and $K_{L F L}$ of a selection of functional groups are depicted in Table 6. The complete list of the GC factors can be found in the supplementary material.

Table 6. Selection of commonly used GC factors for the LFL, UFL, FP, AIT and $K_{L F L}$ model. The complete list of all GC factors can be found in the supplementary material.

\begin{tabular}{|c|c|c|c|c|c|c|c|}
\hline & \multirow{2}{*}{$\begin{array}{c}\text { LFL } \\
{[\text { Vol-\%] }}\end{array}$} & \multirow{2}{*}{$\begin{array}{c}\text { UFL } \\
{[\text { Vol-\%] }}\end{array}$} & \multirow[t]{2}{*}{$\mathrm{FP}[\mathrm{K}]$} & \multicolumn{2}{|c|}{ AIT $[K]$} & \multirow[t]{2}{*}{$K_{L F L}$} \\
\hline & & & & & $\begin{array}{c}\text { Factor } \\
\text { (linear) }\end{array}$ & $\begin{array}{c}\text { Factor } \\
\left(10^{\wedge}\right)\end{array}$ & \\
\hline Type & Constant & 4.53 & 129.96 & 195.22 & 561.19 & 55.19 & -0.0036 \\
\hline $1 \mathrm{st}$ & $\mathrm{CH} 3$ & -0.24 & -1.15 & 8.32 & -74.66 & -0.38 & 1.87 \\
\hline $1 \mathrm{st}$ & $\mathrm{CH} 2$ & -0.23 & -0.14 & 12.49 & 2.19 & 0.14 & -0.20 \\
\hline $1 \mathrm{st}$ & $\mathrm{CH}$ & -0.23 & 0.89 & 7.18 & 94.93 & 0.61 & -1.09 \\
\hline $1 \mathrm{st}$ & $\mathrm{CH} 2=\mathrm{CH}$ & -0.49 & -0.68 & 18.47 & -98.80 & -0.31 & -0.58 \\
\hline $1 \mathrm{st}$ & aromaticCH & -0.22 & -0.46 & 13.19 & -9.84 & -0.13 & 0.40 \\
\hline $1 \mathrm{st}$ & aromaticC & 0.05 & 0.20 & 18.25 & -46.00 & -34.79 & -0.58 \\
\hline $1 \mathrm{st}$ & $\mathrm{OH}$ & 0.06 & -0.76 & 69.04 & 16.20 & -0.19 & -0.88 \\
\hline $1 \mathrm{st}$ & $\mathrm{COOH}$ & 0.00 & -1.03 & 118.40 & 98.45 & -0.03 & -1.01 \\
\hline $1 \mathrm{st}$ & aromaticC-CO & -0.94 & 0.25 & 83.76 & 302.15 & 8.48 & 2.14 \\
\hline $1 \mathrm{st}$ & aromaticC-CHO & -0.07 & -0.40 & 71.33 & -46.26 & 6.07 & -1.62 \\
\hline $1 \mathrm{st}$ & $\mathrm{CHNH} 2$ & -0.33 & -0.19 & 30.68 & 235.16 & 50.42 & - \\
\hline $1 \mathrm{st}$ & $\mathrm{NH} 2$ & 0.02 & -0.13 & 58.96 & -38.58 & -0.04 & - \\
\hline $1 \mathrm{st}$ & $-\mathrm{Br}$ & 1.00 & -1.23 & 47.63 & -94.63 & -0.48 & - \\
\hline $1 \mathrm{st}$ & $-F$ & 1.15 & -0.56 & -9.22 & -221.62 & -0.69 & - \\
\hline $1 \mathrm{st}$ & $-\mathrm{Cl}$ & 0.80 & -1.20 & 21.42 & -143.08 & -0.58 & - \\
\hline $1 \mathrm{st}$ & $\mathrm{Si}$ & -2.08 & 3.34 & 12.06 & 27.78 & 0.02 & - \\
\hline 2nd & $\mathrm{CO}-\mathrm{O}-\mathrm{CO}$ & 0.07 & -0.10 & 5.35 & -57.25 & -0.25 & - \\
\hline 2nd & aromaticC-CH(CH3)2 & -0.24 & -0.27 & 4.54 & 29.19 & 0.23 & - \\
\hline 2nd & $\begin{array}{l}\text { aromaticC-C }(\mathrm{CH} 3) 3 \\
(\mathrm{CHn}=\mathrm{C})(\mathrm{cyclic})-\end{array}$ & $\begin{array}{c}0.01 \\
-0.14\end{array}$ & 0.30 & 13.22 & 21.31 & -0.71 & - \\
\hline 2nd & $\begin{array}{l}\mathrm{CHO}(\mathrm{n} \text { in } 0 . .2) \\
(\mathrm{CHn}=\mathrm{C}) \text { cyclic- } \mathrm{CH} 2\end{array}$ & -0.25 & -0.10 & 16.51 & -15.50 & 0.00 & - \\
\hline 2nd & $(\mathrm{n}$ in $0 . .2)$ & & 0.08 & -5.14 & -41.08 & -0.06 & - \\
\hline 2nd & CHcyclic-CH3 & 0.00 & -1.72 & 1.64 & 1.43 & -0.34 & - \\
\hline $2 \mathrm{nd}$ & CHcyclic-CH2 & -0.02 & -2.25 & 4.37 & 14.03 & 2.23 & - \\
\hline 2 nd & $>$ Ncyclic-CH3 & 0.01 & 0.05 & -23.86 & 60.15 & 0.17 & - \\
\hline
\end{tabular}




\begin{tabular}{|l|l|c|c|c|cc|c|} 
3rd & aromaticRINGs1s2 & 0.12 & -0.01 & -15.44 & 134.03 & 0.22 & - \\
3rd & aromaticRINGs1s3 & -0.01 & -0.07 & -6.41 & 122.77 & 0.21 & - \\
3rd & PYRIDINEs2 & -0.15 & -0.32 & -8.10 & 54.16 & 0.04 & - \\
3rd & aromatic.FUSED[2] & 0.02 & 0.12 & 13.03 & -16.38 & 69.66 & - \\
3rd & aromatic.FUSED[2]s1 & -0.13 & 0.23 & 1.01 & 4.36 & 34.82 & - \\
\hline
\end{tabular}


Table 7 gives an example of predicted values for a variety of organic compounds. The large variety of compounds from different chemical classes illustrates the wide application range of the developed models. More predicted values for different compounds can be found in the supplementary material.

Table 7. Predicted values including the respective 95\% confidence interval for a variety of selected number of chemical compounds. In all cases experimental data (not shown) falls within 95\% confidence interval.

\begin{tabular}{|c|c|c|c|c|c|c|c|c|c|c|c|c|}
\hline \multirow[b]{3}{*}{ n-Heptane } & \multicolumn{3}{|c|}{ LFL [Vol-\%] } & \multicolumn{3}{|c|}{ UFL [Vol-\%] } & \multicolumn{3}{|c|}{$\mathrm{FP}[\mathrm{K}]$} & \multicolumn{3}{|c|}{$\mathrm{AIT}[\mathrm{K}]$} \\
\hline & \multirow{2}{*}{$\frac{\text { Pred. }}{0.75}$} & \multicolumn{2}{|c|}{ 95\% conf.int. } & \multirow{2}{*}{$\frac{\text { Pred. }}{6.28}$} & \multicolumn{2}{|c|}{$95 \%$ conf. int. } & \multirow{2}{*}{$\frac{\text { Pred. }}{274.30}$} & \multicolumn{2}{|c|}{$95 \%$ conf. int. } & \multirow{2}{*}{\begin{tabular}{|r} 
Pred. \\
611.41
\end{tabular}} & \multicolumn{2}{|c|}{$95 \%$ conf. int. } \\
\hline & & 0.63 & 0.87 & & 5.10 & 7.46 & & 271.41 & 277.18 & & 598.42 & 624.40 \\
\hline 2-Methylhexane & 0.71 & 0.59 & 0.82 & 6.21 & 4.84 & 7.57 & 266.46 & 263.26 & 269.65 & 607.46 & 591.98 & 622.95 \\
\hline 3,3-Diethylpentane & 0.44 & 0.25 & 0.62 & 4.67 & 2.61 & 6.73 & 282.92 & 275.80 & 290.04 & 657.55 & 619.25 & 695.84 \\
\hline Cycloheptane & 0.98 & 0.60 & 1.37 & 5.96 & 4.26 & 7.67 & 283.90 & 276.92 & 290.88 & 559.04 & 523.08 & 595.00 \\
\hline 1-Pentene & 1.14 & 0.97 & 1.31 & 9.98 & 8.20 & 11.76 & 246.78 & 242.92 & 250.63 & 601.48 & 583.79 & 619.17 \\
\hline 1-Octene & 0.51 & 0.42 & 0.61 & 6.47 & 4.91 & 8.03 & 284.25 & 280.49 & 288.01 & 599.36 & 582.47 & 616.24 \\
\hline Benzene & 1.20 & 0.06 & 2.34 & 8.00 & 0.78 & 15.22 & 274.35 & 267.50 & 281.21 & 770.73 & 730.92 & 810.55 \\
\hline Toluene & 1.09 & 0.64 & 1.54 & 7.87 & 3.78 & 11.95 & 293.78 & 288.77 & 298.79 & 765.55 & 738.31 & 792.79 \\
\hline Ethylbenzene & 1.04 & 0.51 & 1.57 & 7.25 & 3.70 & 10.79 & 305.57 & 300.91 & 310.24 & 720.08 & 693.02 & 747.13 \\
\hline o-Xylene & 1.11 & 0.54 & 1.68 & 7.64 & 2.49 & 12.78 & 297.75 & 291.30 & 304.21 & 754.03 & 715.95 & 792.12 \\
\hline Propanal & 3.12 & 2.65 & 3.59 & 20.42 & 17.21 & 23.63 & 260.91 & 254.59 & 267.23 & 536.40 & 506.65 & 566.16 \\
\hline Butanal & 2.40 & 2.00 & 2.80 & 17.67 & 14.68 & 20.66 & 273.40 & 267.15 & 279.64 & 536.33 & 506.71 & 565.94 \\
\hline Acrolein & 2.80 & 2.06 & 3.54 & 29.22 & 22.91 & 35.53 & 259.44 & 247.96 & 270.91 & 517.71 & 448.45 & 586.96 \\
\hline Benzaldehyde & 1.40 & 0.26 & 2.54 & 8.50 & 1.25 & 15.75 & 332.49 & 320.44 & 344.54 & 556.89 & 499.89 & 613.90 \\
\hline 2-Heptanone & 0.97 & 0.67 & 1.28 & 6.97 & 4.59 & 9.35 & 313.93 & 307.13 & 320.73 & 668.05 & 633.43 & 702.66 \\
\hline Ethanol & 3.33 & 2.98 & 3.68 & 16.63 & 14.31 & 18.96 & 285.07 & 281.55 & 288.59 & 637.56 & 619.58 & 655.54 \\
\hline 1-Propanol & 2.55 & 2.28 & 2.83 & 14.40 & 12.44 & 16.36 & 297.56 & 294.19 & 300.92 & 636.24 & 618.67 & 653.81 \\
\hline
\end{tabular}




\begin{tabular}{|c|c|c|c|c|c|c|c|c|c|c|c|c|}
\hline Isopropanol & 2.08 & 1.43 & 2.73 & 11.26 & 7.21 & 15.31 & 283.21 & 277.34 & 289.09 & 646.61 & 612.04 & 681.18 \\
\hline 1-Butanol & 1.96 & 1.72 & 2.20 & 12.46 & 10.65 & 14.27 & 310.05 & 306.79 & 313.30 & 635.02 & 617.80 & 652.24 \\
\hline 1-Pentanol & 1.50 & 1.28 & 1.72 & 10.78 & 9.02 & 12.55 & 322.54 & 319.35 & 325.73 & 633.89 & 616.95 & 650.83 \\
\hline n-Butyric acid & 2.21 & 1.77 & 2.65 & 10.94 & 7.65 & 14.24 & 346.91 & 341.55 & 352.28 & 634.80 & 611.79 & 657.80 \\
\hline n-Pentanoic acid & 1.70 & 1.35 & 2.04 & 9.47 & 6.56 & 12.38 & 359.40 & 354.09 & 364.71 & 633.46 & 610.76 & 656.17 \\
\hline $\begin{array}{l}\text { Methyl tert-butyl } \\
\text { ether }\end{array}$ & 1.42 & 0.91 & 1.94 & 6.90 & 4.90 & 8.90 & 253.62 & 247.77 & 259.47 & 630.16 & 603.54 & 656.78 \\
\hline Methyl ethyl ether & 2.31 & 2.00 & 2.61 & 15.08 & 13.20 & 16.95 & 245.01 & 240.91 & 249.11 & 578.60 & 558.38 & 598.82 \\
\hline Divinyl ether & 1.70 & 0.56 & 2.84 & 27.00 & 19.75 & 34.25 & 226.15 & 203.21 & 249.09 & 623.23 & 492.98 & 753.48 \\
\hline 1,4-Dioxane & 2.36 & 1.87 & 2.84 & 21.06 & 16.18 & 25.93 & 284.78 & 275.73 & 293.83 & 538.61 & 496.87 & 580.36 \\
\hline tert-Butyl ethyl ether & 1.15 & 0.72 & 1.57 & 6.32 & 4.19 & 8.44 & 263.03 & 257.54 & 268.51 & 616.04 & 592.70 & 639.37 \\
\hline 1,2-Dichloroethane & 4.93 & 4.30 & 5.56 & 19.11 & 13.60 & 24.62 & 299.20 & 292.07 & 306.32 & 701.28 & 651.93 & 750.64 \\
\hline 1,2-Dichloropropane & 3.57 & 2.69 & 4.45 & 14.50 & 7.25 & 21.75 & 288.60 & 281.12 & 296.08 & 735.08 & 663.66 & 806.51 \\
\hline Isopropyl chloride & 2.65 & 1.92 & 3.38 & 18.88 & 13.59 & 24.18 & 246.57 & 238.40 & 254.73 & 712.43 & 635.55 & 789.30 \\
\hline 1-Chloropentane & 1.69 & 1.48 & 1.90 & 8.57 & 6.94 & 10.20 & 292.99 & 288.99 & 297.00 & 653.07 & 627.34 & 678.80 \\
\hline Dimethylamine & 2.80 & 1.66 & 3.94 & 14.40 & 7.15 & 21.65 & 223.15 & 200.21 & 246.09 & 599.55 & 457.37 & 741.73 \\
\hline Triethylamine & 1.29 & 0.24 & 2.33 & 8.69 & 2.88 & 14.50 & 264.68 & 256.03 & 273.34 & 554.89 & 482.22 & 627.56 \\
\hline Pyridine & 1.80 & 0.66 & 2.94 & 12.00 & 4.75 & 19.25 & 287.83 & 277.45 & 298.21 & 735.61 & 662.44 & 808.78 \\
\hline Aniline & 1.37 & 0.82 & 1.91 & 10.25 & 3.86 & 16.65 & 345.81 & 339.13 & 352.48 & 768.19 & 724.24 & 812.13 \\
\hline Thiophene & 1.29 & 0.45 & 2.13 & 7.96 & 3.50 & 12.41 & 281.11 & 268.08 & 294.14 & 640.15 & 569.30 & 710.99 \\
\hline Dimethyl sulfoxide & 2.60 & 1.46 & 3.74 & 28.50 & 21.25 & 35.75 & 361.00 & 338.06 & 383.94 & 492.34 & 350.16 & 634.52 \\
\hline $\begin{array}{l}\text { n,n-Dimethylacet- } \\
\text { amide }\end{array}$ & 1.80 & 0.66 & 2.94 & 11.50 & 4.25 & 18.75 & 336.15 & 313.21 & 359.09 & 631.70 & 489.52 & 773.88 \\
\hline 2-Methoxyethanol & 2.20 & 1.64 & 2.76 & 19.60 & 15.90 & 23.30 & 304.56 & 299.42 & 309.70 & 578.47 & 547.32 & 609.63 \\
\hline n-Ethylaniline & 1.60 & 0.46 & 2.74 & 9.50 & 2.25 & 16.75 & 360.82 & 344.60 & 377.04 & 697.72 & 643.08 & 752.35 \\
\hline Vinyltrichlorosilane & 3.71 & 2.82 & 4.60 & 50.72 & 43.55 & 57.90 & 290.02 & 278.46 & 301.57 & 628.90 & 559.44 & 698.37 \\
\hline $\begin{array}{l}\text { Ethylene glycol } \\
\text { monopropyl ether }\end{array}$ & 1.30 & 0.99 & 1.60 & 14.68 & 12.10 & 17.26 & 329.54 & 324.57 & 334.52 & 577.20 & 546.36 & 608.04 \\
\hline 1-Chloro-2,4- & 2.19 & 1.13 & 3.25 & 22.00 & 14.75 & 29.25 & 462.69 & 451.75 & 473.64 & 677.46 & 593.67 & 761.26 \\
\hline
\end{tabular}




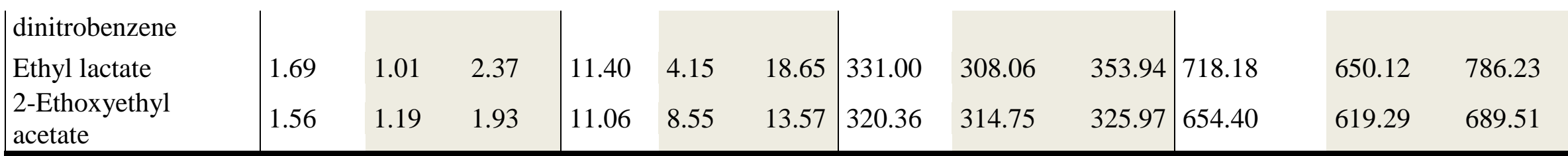


Figure 5 shows the results of the covariance-based uncertainty analysis, exemplified for the case of LFL. The experimental and the predicted values of LFL with the respective 95\%-confidence interval of the prediction highest value and for every substance are shown. The compounds are ordered from lowest to highest given an index number respectively. The 95\%-confidence interval is a narrow band that includes the experimental values. The detailed covariance-based uncertainty analysis is another advantage of the developed GC models. Whereas the majority of the other authors define the quality of their model only with $A R E$, we can provide the $95 \%$ confidence interval for every prediction. This additional information, i.e. the reliability of the prediction, can be vital in the context of a quantitative safety-related risk analysis. For example it is possible to use the lower-bound value of the confidence interval in a conservative analysis approach. In fact, the lower bound of the confidence interval for LFL, is approximately $20 \%$ of the LFL values. The latter is commonly used as a rule of thumb in quantitative risk analysis (QRA) studies [45].

Although the extension to mixtures lies far beyond the scope of this work, users can calculate the properties of mixtures from the current pure component model by applying simple mixing rules (e.g. le Chatelier's mixing rule for flammability limit [46]). 


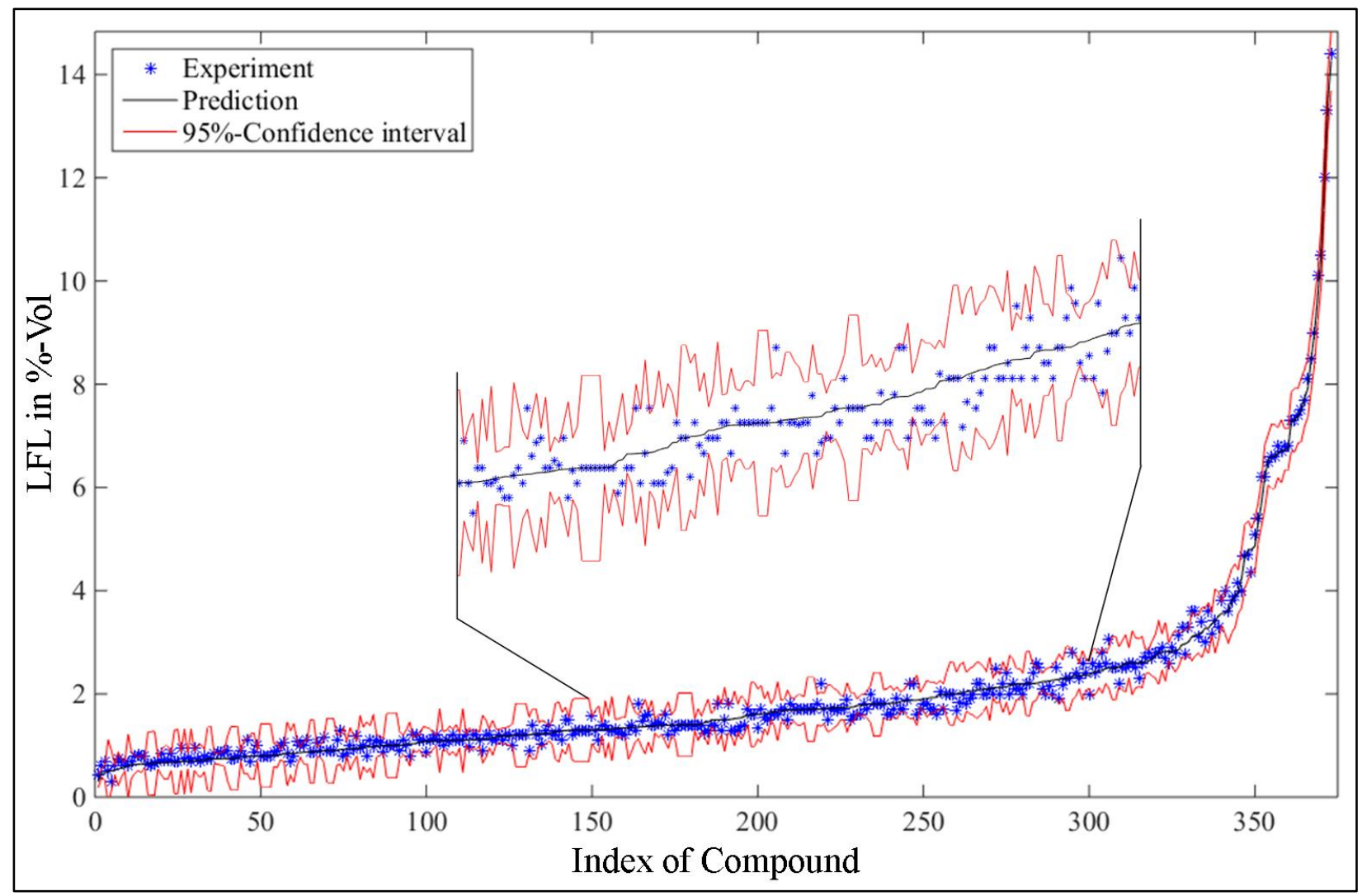

Figure 5. Experimental as well as predicted value of LFL for every compound with 95\%confidence intervals generated by covariance-based uncertainty analysis. A section of the plot is enlarged to show the distribution of the experimental values around the prediction.

The results of the calculation of the Akaika information criterion $(A I C)$ for small sample for the developed temperature-dependent model compared to the one developed by Rowley et al. [8] is shown Table 8 . The temperature-dependent LFL model developed in this study has been evaluated for different temperatures. These were used to calculate the sum of squared errors and subsequently $A I C$. 
Table 8. Akaika information criterion (AIC) for small sample with SSE (sum of squared errors of the fit), $n$ (number of experimental data points), $p$ (total number of parameters.

\begin{tabular}{lcccc}
\hline & $S S E$ & $n$ & $p$ & AIC \\
\hline Current model & 3.39 & 16 & 22 & 45.6 \\
\hline Rowley et al. & & & & 67.3 \\
\hline
\end{tabular}

For the developed model in this study the total number of parameters $p$ is consisting of the 21 GC factors, and LFL(T=298K). For the study of Rowley et al. the number of parameters $p$ is assumed under assumption that the heat capacity and the heat of combustion needs to be predicted, which is needed if the temperature-dependent LFL is calculated from predicted values only (according to Eq. (8)). The simplest GC based model for the prediction of the heat capacity is Joback and Reid's method with 20 parameters. The easiest way to predict the heat of combustion is deriving it from the heat of formation using Benson's method with approximately 12 parameters.

AIC is lower for the newly developed model in this study, although the model of Rowley et al. shows a better fitting to the experimental data. The $A I C$ calculation enforces the fact that the newly developed model using the lumped parameter is a sparse model and should therefore be selected. 


\subsection{Demonstration of model application}

The developed models allow calculating the safety-properties from the molecular structure only and include an uncertainty analysis. Figure 6 depicts the result of example calculations with the developed GC MG models for 3-Hexanol. It provides an overall picture of the major flammability property predictions including the corresponding 95\% confidence interval.

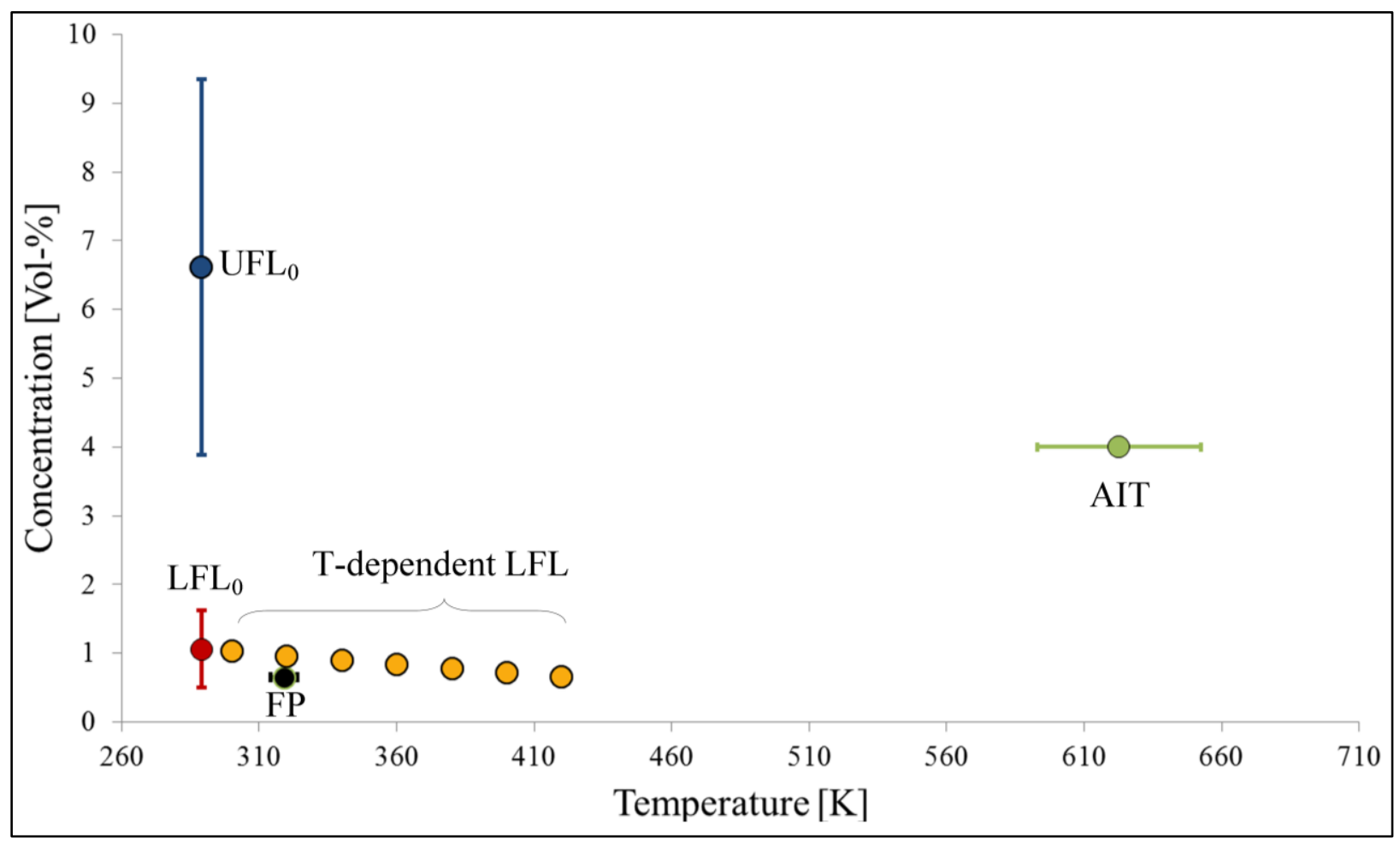

Figure 6. Overview of the generated flammability-related properties by the developed GC MG models including 95\% confidence interval: $\mathrm{LFL}_{0}$ (lower flammability limit at $\mathrm{T}=298 \mathrm{~K}$ ), $\mathrm{UFL}_{0}$ (upper flammability limit $\mathrm{T}=298 \mathrm{~K}$ ), FP (flash point), AIT (auto ignition temperature) and Temperature-dependent LFL (without uncertainty).

In order to demonstrate the simplicity of the model application, the prediction of LFL at $298 \mathrm{~K}$ (single point) including uncertainty and at a different temperature $(350 \mathrm{~K})$ point and using the temperature-dependence is shown by the example of 3-Hexanol. The calculation procedure for UFL, FP and AIT is analogous. The respective parameter values, covariance matrices and 
jacobians for the model are given in the supplementary material. Further information (e.g. on the identification of the GC factor for a new molecule) can also be provided by the authors upon request.

1) The MG GC parameters of the compound have to be identified according to the rules set by Marrero and Gani [37]. These rules state how to identify 1st, 2nd and 3rd order parameters from Simplified Molecular Input Line Entry Specification (SMILES). The structure of 3-Hexanol is depicted in Figure 7 and the corresponding Marrero Gani GC factors collected from the supplementary material in Table 9. The structure of 3-Hexanol is relatively simple, hence it does not contain 3rd order groups. The universal constant from robust regression is $L F L_{\text {const }}=4.53 \mathrm{Vol}$ $\%$.

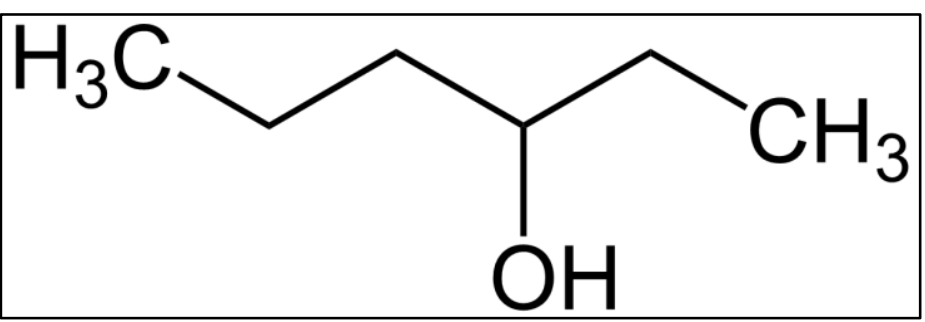

Figure 7. Structure of 3-Hexanol [47].

Table 9. Group contribution factors of 3-Hexanol, obtained from GC factor sheet.

\begin{tabular}{lcc}
\hline 1st order groups $j$ & $N_{j}$ & $C_{j}$ \\
\hline $\mathrm{CH} 3$ & 2 & -0.24 \\
\hline $\mathrm{CH} 2$ & 3 & -0.23 \\
\hline $\mathrm{CH}$ & 1 & -0.23 \\
\hline $\mathrm{OH}$ & 1 & 0.06 \\
\hline 2nd order group $k$ & $M_{k}$ & $D_{k}$
\end{tabular}




\section{$\overline{\mathrm{CHOH}}$}

1

$-0.11$

2) The overall model equation according to Eq. (3) can be simplified. The GC factors are taken from Table 9 and can be inserted into Eq. (23). Hence, LFL of 3-Hexanol can be calculated according in Eq. (24). The unit of LFL is Volume-\% (Vol.\%) of the chemical in air.

$$
\begin{gathered}
L F L=L F L_{\text {const }} * \exp \left(\sum_{j} N_{j} C_{j}+\sum_{k} M_{k} D_{k}+\sum_{l} E_{l} O_{l}\right) \\
L F L=L F L_{\text {const }} * \exp \left(\sum_{j} N_{j} C_{j}+\sum_{k} M_{k} D_{k}\right)
\end{gathered}
$$

$$
\begin{aligned}
L F L & =4.53 * \exp (2 \cdot-0.24+3 \cdot-0.23+1 \cdot-0.23+1 \cdot-0.06+1 \cdot-0.11) \text { Vol. } \% \\
& =1.06 \mathrm{Vol} . \%
\end{aligned}
$$

3) Using the parameter covariance matrix $\operatorname{COV}\left(\theta^{*}\right)$ and the sensitivity matrix $J$ that can be found in the supplementary material for the respective groups (see Table 10), it is possible to compute the respective confidence interval for the prediction as depicted in Eq. (25) and (26).

Table 10. Parameter covariance matrix $\operatorname{COV}\left(\theta^{*}\right)$ and local sensitivity matrix $J$.

\begin{tabular}{c|c|c|c|c|c|c} 
& $L F L_{\text {const }}$ & $\mathrm{CH} 3$ & $\mathrm{CH} 2$ & $\mathrm{CH}$ & $\mathrm{OH}$ & $\mathrm{CHOH}$ \\
\hline$L F L_{\text {const }}$ & 0.99 & & & & & \\
\hline $\mathrm{CH} 3$ & -0.11 & 0.012 & & & & \\
\hline $\mathrm{CH} 2$ & $-3.1 \cdot 10^{-4}$ & $-1.5 \cdot 10^{-4}$ & $5.1 \cdot 10^{-4}$ & & & \\
\hline $\mathrm{CH}$ & -0.11 & -0.012 & $1.6 \cdot 10^{-4}$ & 0.025 & & \\
\hline
\end{tabular}




\begin{tabular}{c|c|c|c|c|c|c}
\hline $\mathrm{OH}$ & -0.093 & $-9.6 \cdot * 10^{-3}$ & $-3.4 \cdot 10^{-5}$ & $-9.8 \cdot 10^{-3}$ & 0.58 & \\
\hline $\mathrm{CHOH}$ & $2.9 \cdot 10^{-3}$ & $-5.3 \cdot 10^{-5}$ & $-3.3 \cdot 10^{-4}$ & $-2.6 \cdot 10^{-4}$ & $-3.4 \cdot 10^{-3}$ & 0.042 \\
\hline$\frac{\delta L F L}{\delta L F L_{\text {const }}}$ & $\frac{\delta L F L}{\delta C H 3}$ & $\frac{\delta L F L}{\delta C H 2}$ & $\frac{\delta L F L}{\delta C H}$ & $\frac{\delta L F L}{\delta O H}$ & $\frac{\delta L F L}{\delta C H O H}$ \\
\hline 0.43 & 1.5 & 0.97 & 0.15 & $-1.7^{*} 10^{-3}$ & 0.014 \\
\hline \multicolumn{7}{c}{$L F L_{1-\alpha_{t} / 2}^{\text {pred }}=L F L_{\text {pred }} \pm \sqrt{\text { diag }\left(J\left(\theta^{*}\right) C O V\left(\theta^{*}\right) J\left(\theta^{*}\right)^{T}\right)} \cdot t\left(n-p, \alpha_{t} / 2\right)$} \\
$L F L_{1-\alpha_{t / 2}}^{\text {pred }}=1.06 \mathrm{Vol} . \% \pm 0.56 \mathrm{Vol.} \%$
\end{tabular}

The above can be compared to the method of Gmehling et al. [48], who predicted LFL for 3Hexanol to be 1.29 Vol.\% [16]. Hence, this value falls squarely within the predicted 95\%confidence interval of the model verifying the reliability of the model for this particular point.

4) In order to account for the temperature-dependency it is necessary to calculate $K^{L F L}$ with the developed MG GC models. LFL of 3-Hexanol should be calculated at a temperature of $320 \mathrm{~K}$ following Eq. (8) and (9). The value calculated under point 3 can be taken as the reference value $\operatorname{LFL}\left(T_{\text {ref }}=298 \mathrm{~K}\right)=1.06 \mathrm{Vol} . \%$.

$K^{L F L}$ according to the developed model in Eq. (11) is given by:

$$
K_{3-\text { Hexanol }}^{L F L}=\frac{K_{\text {const }}^{L L L}}{\sum_{j} N_{j} C_{j}}=3.05 \cdot 10^{-3}
$$

Using the above values, LFL of 3-Hexanol at the specific temperature of $320 \mathrm{~K}$ is given by: 


$$
\begin{gathered}
L F L(T=320)=L F L\left(T_{\text {ref }}\right)+\cdot K_{3-\text { Hexanol }}^{L F L} \cdot\left(T-T_{\text {ref }}\right) \\
L F L(T=320 K)=0.97 \mathrm{Vol} . \%
\end{gathered}
$$

The uncertainty of the temperature-dependent LFL calculation is huge, around 100\% of the estimate value (not shown Eq. (29) and in Figure 6). The reason for this high uncertainty is the limited number of compounds with temperature-dependent LFL data, hence the term $t\left(n-p, \alpha_{t} / 2\right)$ becomes very large for $K^{L F L}$. Higher reliability of the prediction can only be achieved by using more experimental data for the parameter estimation. However, the new GC based temperature-dependent model demonstrated above provides an approximation where the true value of the LFL is most likely to be found. The latter is useful for performing safety analysis under lack of experimental data, which is the second best alternative. 


\section{Conclusion}

In this study, a new GC method has been developed for the calculation of LFL and UFL as well as a new model for estimating temperature dependence of LFL. Furthermore, the parameters for the previous model of FP and AIT have been improved thanks to expanded data sets and a comprehensive parameter estimation methodology. The systematic parameter estimation and uncertainty analysis provides uncertainty information for the single point predictions.

- The developed LFL and UFL model has a higher accuracy than existing GC models and is much simpler to apply than current ANN or QSPR models.

- A temperature-dependent LFL model based on a GC model for a lumped parameter has been developed.

- The advanced parameter estimation using (robust regression) and the systematic outlier treatment using the empirical $\mathrm{CDF}$ together with additional experimental data could improve the existing GC MG model for FP and AIT.

- The report of the $95 \%$-confidence interval of the predicted value for the safety-related properties provided important information on the uncertainty (reliability) of the predicted values. The latter is crucial in a quantitative risk assessment as it provides a safety factor for LFL analysis.

- The simplicity of the model application has been demonstrated for the 3-Hexanol as a motivating example. 
- The availability of a class of GC models for predicting flammability related properties of chemicals is expected to facilitate the quantitative risk assessment as part of process safety analysis. 


\section{Supporting information}

The Supporting Information is available on the website:

Group contribution factors for and formulas for all developed models are shown in tabular form. Furthermore, examples of predicted values including $95 \%$ confidence interval for a variety of chemical compounds are given.

The authors developed a software tool where the developed models are implemented. Please contact the corresponding author for more information.

\section{Author information}

\section{Corresponding Author}

*Tel.: +45 45252806, E-mail address: gsi@kt.dtu.dk

\section{Author Contributions}

The manuscript was written through contributions of all authors. All authors have given approval to the final version of the manuscript.

\section{Funding Sources}

This work was funded by the Innovation Fund Denmark under the Thermcyc project. 


\section{References}

[1] R. Gani, J.P. O’Connell, Properties and CAPE: From present uses to future challenges, Comput. Chem. Eng. 25 (2001) 3-14.

[2] A.S. Hukkerikar, R.J. Meier, G. Sin, R. Gani, A method to estimate the enthalpy of formation of organic compounds with chemical accuracy, Fluid Phase Equilib. 348 (2013) $23-32$.

[3] J. Frutiger, C. Marcarie, J. Abildskov, G. Sin, A comprehensive methodology for development, parameter estimation, and uncertainty analysis of group contribution based property models - an application to heat of combustion, J. Chem. Eng. Data. 61 (2016) $602-613$.

[4] M.E. Paté-Cornell, Uncertainties in risk analysis: Six levels of treatment, Reliab. Eng. Syst. Saf. 54 (1996) 95-111.

[5] M.G. Zabetakis, Flammability characteristics of combustible gases and vapors, Washington DC, 1965.

[6] D.A. Crowl, J.F. Louvar, Definitions of fires and explosions, in: Chem. Process Saf., Prentice Hall International Series in the Physical and Chemical Engineering Sciences, Boston, 2011: pp. 241-243.

[7] M. Vidal, W.J. Rogers, J.C. Holste, M.S. Mannan, A review of estimation methods for flash points and flammability limits, Process Saf. Prog. 23 (2004) 47-55.

[8] J.R. Rowley, R.L. Rowley, W. V Wilding, Estimation of the lower flammability limit of organic compounds as a function of temperature., J. Hazard. Mater. 186 (2011) 551-557.

[9] A.A. Shimy, Calculating flammability characteristics of hydrocarbons and alcohols, Fire 
Technol. 6 (1970) 135-139.

[10] N.V. Solovev, A.N. Baratov, Lower limit of flammability of hydrocarbon-air mixtures as a function of the molecular structure of the combustible component, Russ. J. Phys. Chem. 34 (1960) 1661-1670.

[11] E. Oehley, Ableitung empirischer Gleichungen fur die untere Explosionsgrenze und den Flammpunkt, Chemie Ingenieu Tech. 25 (1953) 399-403.

[12] Y.N. Shebeko, A. V Ivanov, T.M. Dmitrieva, Methods of Calculating the Lower Concentration Limits of Ignition of Gases and Vapors in Air., Sov. Chem. Ind. 15 (1983) $311-317$.

[13] S. Kondo, Y. Urano, K. Tokuhashi, A. Takahashi, K. Tanaka, Prediction of flammability of gases by using F-number analysis, J. Hazard. Mater. 82 (2001) 113-128.

[14] S. Kondo, A. Takahashi, K. Tokuhashi, Experimental exploration of discrepancies in Fnumber correlation of flammability limits, J. Hazard. Mater. 100 (2003) 27-36.

[15] W.H. Seaton, Group contribution method for predicting the lower and the upper flammable limits of vapors in air, J. Hazard. Mater. 27 (1991) 169-185.

[16] R. L. Rowley, W. V. Wilding, J. L. Oscarson, T. A. Knotts, N. F. Giles, DIPPR ${ }^{\circledR}$ Data Compilation of Pure Chemical Properties, Design Institute for Physical Properties, AIChE, New York, NY, (2014).

[17] T. a. Albahri, Flammability characteristics of pure hydrocarbons, Chem. Eng. Sci. 58 (2003) 3629-3641.

[18] F. Gharagheizi, Quantitative Structure - Property Relationship for Prediction of the Lower Flammability Limit of Pure Compounds, Energy \& Fuels. 22 (2008) 3037-3039.

[19] Y. Pan, J. Jiang, R. Wang, H. Cao, Y. Cui, A novel QSPR model for prediction of lower 
flammability limits of organic compounds based on support vector machine, J. Hazard. Mater. 168 (2009) 962-969.

[20] Y. Pan, J. Jiang, R. Wang, H. Cao, Y. Cui, Prediction of the upper flammability limits of organic compounds from molecular structures, Ind. Eng. Chem. Res. 48 (2009) 50645069.

[21] F. Gharagheizi, A new group contribution-based model for estimation of lower flammability limit of pure compounds., J. Hazard. Mater. 170 (2009) 595-604.

[22] T. a. Albahri, Prediction of the lower flammability limit percent in air of pure compounds from their molecular structures, Fire Saf. J. 59 (2013) 188-201.

[23] F. Gharagheizi, Prediction of upper flammability limit percent of pure compounds from their molecular structures., J. Hazard. Mater. 167 (2009) 507-10.

[24] J.A. Lazzús, Neural network/particle swarm method to predict flammability limits in air of organic compounds, Thermochim. Acta. 512 (2011) 150-156.

[25] M. Bagheri, M. Rajabi, M. Mirbagheri, M. Amin, BPSO-MLR and ANFIS based modeling of lower flammability limit, J. Loss Prev. Process Ind. 25 (2012) 373-382. doi:10.1016/j.jlp.2011.10.005.

[26] M.S. High, R.P. Danner, Prediction of upper flammability limit by a group contribution method, Ind. Eng. Chem. Res. 26 (1987) 1395-1399.

[27] G. Shu, B. Long, H. Tian, H. Wei, X. Liang, Evaluating upper flammability limit of low hydrocarbon diluted with an inert gas using threshold temperature, Chem. Eng. Sci. 138 (2015) 810-813. doi:10.1016/j.ces.2015.09.013.

[28] G. Shu, B. Long, H. Tian, H. Wei, X. Liang, Flame temperature theory-based model for evaluation of the flammable zones of hydrocarbon-air- $\mathrm{CO} 2$ in mixtures, J. Hazard. Mater. 
294 (2015) 137-144.

[29] A.Z. Mendiburu, J.A. de Carvalho, C.R. Coronado, Estimation of lower flammability limits of $\mathrm{C}-\mathrm{H}$ compounds in air at atmospheric pressure, evaluation of temperature dependence and diluent effect, J. Hazard. Mater. 285 (2015) 409-418.

[30] A.Z. Mendiburu, J.A. de Carvalho, C.R. Coronado, Estimation of upper flammability limits of $\mathrm{C}-\mathrm{H}$ compounds in air at atmospheric pressure, evaluation of temperature dependence and diluent effect, J. Hazard. Mater. 304 (2016) 512-521.

[31] M.G. Zabetakis, S. Lambiris, G.S. Scott, Flame temperatures of limit mixtures, in: 7th Symp. Combust., 1959: p. 484.

[32] L.G. Britton, Using heats of oxidation to evaluate flammability hazards, Process Saf. Prog. $21(2002) 31-54$.

[33] L.G. Britton, D.J. Frurip, Further uses of the heat of oxidation in chemical hazard assessment, Process Saf. Prog. 22 (2003) 1-19.

[34] J.R. Rowley, R.L. Rowley, W.V. Wilding, Experimental determination and reexamination of the effect of initial temperature on the lower flammability limit of pure liquids, J. Chem. Eng. Data. 55 (2010) 3063-3067.

[35] L. Catoire, V. Naudet, Estimation of temperature-dependent lower flammability limit of pure organic compounds in air at atmospheric pressure, Process Saf. Prog. 24 (2005) 130137.

[36] A.S. Hukkerikar, B. Sarup, A. Ten Kate, J. Abildskov, G. Sin, R. Gani, Groupcontribution $+(\mathrm{GC}+)$ based estimation of properties of pure components: Improved property estimation and uncertainty analysis, Fluid Phase Equilib. 321 (2012) 25-43.

[37] J. Marrero, R. Gani, Group-contribution based estimation of pure component properties, 
Fluid Phase Equilib. 183-184 (2001) 183-208.

[38] J. Frutiger, J. Abildskov, G. Sin, Outlier treatment for improving parameter estimation of group contribution based models for upper flammability limit, in: K. V. Gernaey, J.K. Huusom, R. Gani (Eds.), 12th Int. Symp. Process Syst. Eng. 25th Eur. Symp. Comput. Aided Process Eng., Copenhagen, 2015.

[39] H.F. Coward, G.W. Jones, Limits of flammability of gases and vapors, Washington DC, 1952.

[40] K. Joback, R. Reid, Estimation of pure-component properties from group-contribution, Chem. Eng. Commun. 57 (1987) $233-243$.

[41] G. Seber, C. Wild, Nonlinear Regression, John Wiley \& Sons, Inc., Hoboken, NJ, USA, 1989.

[42] K.P. Burnham, D.R. Andersen, Multimodel Inference: Understanding AIC and BIC in Model Selection, Sociol. Methods Res. 33 (2004) 261-304.

[43] T. a. Albahri, Structural Group Contribution Method for Predicting the Octane Number of Pure Hydrocarbon Liquids, Ind. Eng. Chem. Res. 42 (2003) 657-662.

[44] K.C. Kroenlein, R. Chirico, V. Diky, A. Bazyleva, J. Magee, Thermophysical Property Reliability Issues in the Context of Automated Consumption, in: 19th Symp. Thermophys. Prop., Boulder, CO, 2015.

[45] Center for Chemical Process Safety, Guidelines for Vapor Cloud Explosion, Pressure Vessel Burst, BLEVE and Flash Fire Hazards, 2nd Editio, Wiley, 2011.

[46] D.A. Crowl, J.F. Louvar, Chemical process safety, 2nd ed., Prentice Hall International Series in the Physical and Chemical Engineering Sciences, New Jersey, 2013.

[47] N. Mills, ChemDraw Ultra 10.0, J. Am. Chem. Soc. 128 (2006) 13649-13650. 
[48] J. Gmehling, P. Rasmussen, Flash Points of Flammable Liquid Mixtures using UNIFAC, Ind. Eng. Chem. Fundam. (1982) 186-188. 